\title{
BIODEGRADATION AND RECYCLING POTENTIAL OF BARRIER COATED PAPERBOARDS
}

\author{
Waranyou Sridach, ${ }^{\mathrm{a}}$ Kevin T. Hodgson, ${ }^{\mathrm{b}}$ and Mousa M. Nazhad* ${ }^{\mathrm{c}}$ \\ Four commercial barrier coated boards (i.e., internally-sized uncoated \\ board, one-side polyethylene coated board, double-side polyethylene \\ coated board, and multilayer laminated board) were examined for \\ biodegradation using a soil burial approach on a laboratory scale. It was \\ observed that the base-boards were fully biodegradable in a matter of \\ weeks or months, and the degradation process could be accelerated \\ either by sample size modification or enrichment of the soil microbial \\ population. Freezing pretreatment of boards or the fiber directionality of \\ boards had no influence on the rate of degradation. The boards were \\ also found to be recyclable following a simple procedure of re-slushing \\ and screening. The base-boards became almost fully separated from \\ the polyethylene coated material without any special pretreatment.
}

Key words: Biodegradation, Base-board, Barrier coating, Recycling, Soil burial, Inoculum, Microorganism, Weight loss, Tensile strength.

Contact information: a:Paper Science and Engineering Program, College of Forest Resources, University of Washington, 98195-2100, Lecturer, Prince of Songkhla University, Thailand; b: Paper Science and Engineering Program, University of Washington, Seattle, WA USA; c: Visiting Scientist, Paper Science and Engineering Program, University of Washington, Seattle, WA USA; *Corresponding author: mousanazhad@ait.ac.th, mousan@u.washington.edu, mousanazhad@yahoo.com

\section{INTRODUCTON}

Paper and paperboard are by far the most prevalent sources of packaging materials the world over. Global production of paper for wrapping, packaging, corrugated boxes and other containers increased 75 percent over just the last 5 years (World Resources 2001). This rapid growth in paper packaging has also had the effect of exacerbating solid waste handling problems. In the United States alone, paper accounts for nearly 40 percent of municipal solid waste. Disposal of paper products in landfill sites can lead to emissions of the greenhouse gas methane, and incinerating chlorine-bleached paper at landfills may release dioxins into the atmosphere. As a result, the management of this waste has become one of the more pressing issues of the modern age.

Bringing solid waste issues under control has led to numerous government, private-sector, and voluntary initiatives to reduce the volume of waste going to landfills. This can be accomplished by: 1) increasing the recycling rate, 2) incineration as a source of energy, or 3) biodegradation by using microorganisms (Andrady et al. 1992; Sridach et al. 2006). The European Union has set strict guidelines, such as the Packaging Waste Directive (94/62EU) and Landfill Directive (99/31/EC) to help effectively manage these solid waste problems.

Due to a continual reduction of landfill sites in the US and Europe, biodegradability is considered a desirable alternative in the management of solid waste. 
The paper and paperboard industry is also attempting to replace existing polymer coating formulations for paper and board with biodegradable coating formulations (Andrady et al. 1992; Sridach et al. 2006). Paperboard itself (without any coatings) is either almost pure holocellulose with a minimum amount of residual lignin (about $0.2 \%$ ), or can contain up to $20 \%$ lignin depending on the end use of the board.

Biodegradability of polymers can be tested using screening tests which simulate in-situ conditions (Fig. 1). Screening tests by either enzymatic or aquatic means are inexpensive and fast, but real-life tests can be laborious and expensive. Neither of these two types of processes, however, actually simulate the conditions truly present in landfills.

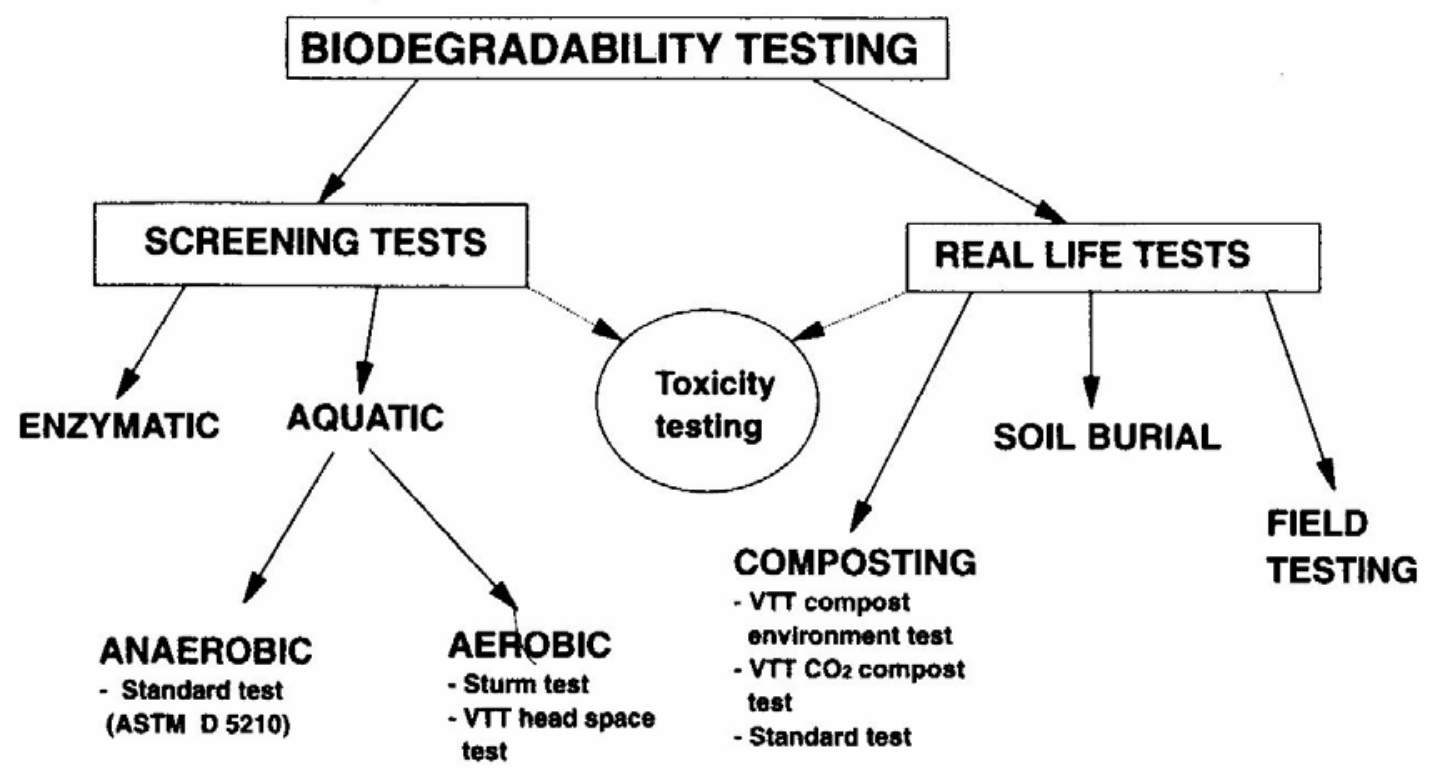

Fig. 1. Biodegradability testing of solid polymers (Itavaara and Vikman 1996).

Biodegradability and the rate of biodegradation depend in general on the substrate structure, the substrate composition as well as the microorganisms which are present (Ramos et al. 1993). Also, the rate of biodegradation decreases with the progress of the reaction. The cause of this decline in degradation rate is not yet totally clear. Although some substrate-related factors (such as crystallinity of cellulose) can perhaps partially explain why there is a gradual decrease in the hydrolysis rate of cellulose, several factors associated with the nature of the enzyme system used have also been suggested as being key to the decrease in rate of cellulose hydrolysis. These include shearing and thermal inactivation of enzymes, irreversible adsorption or nonspecific binding of cellulases, and end-product inhibition of the cellulose complex (Ramos et al. 1993). Ramos et al. (1993) observed that a short incubation time of 2 hours was all that was required to reduce the fiber length of bleached Kraft pulp (i.e. 48 fraction) from 920 to 170 microns. This observation suggests that the decrease in degradation rate most probably occurs at the stage of cellobiose conversion to sugar monomers. Also, the hydrolysis rate is usually accelerated by addition of beta-glucosidase to the mixture (Itavaara et al. 1999). 
The degradation of lignin in a composting environment is almost comparable to soil degradation in its magnitude (Tuomela et al. 2000). In a composting environment, bleached Kraft pulp, stone groundwood (SGW) pulp, and sawdust were degraded $86 \%$, $38 \%$, and $10 \%$, respectively, in 50 days at a temperature of $50^{\circ} \mathrm{C}$. These results indicate the fact that lignin is a major barrier in degradation of lignocellulosic materials (Tuomela et al. 2001). Although the lignin content of both sawdust and SGW in the cell wall was similar, the degradation rate of SGW was almost fourfold that of sawdust. This has been attributed to more accessible surface of the SGW fibers as compared to sawdust (Tuomela et al. 2001). Nazhad et al. (1995) also proposed similar reasoning in interpreting the differences in degradation of different cellulosic substrates.

Soil bacteria (actinomycetes) and fungi are both capable of producing cellulolytic as well as lignolytic enzymes. Fungi including Trichoderma, Penicillium, and Fusarium spp. are all efficient producers of cellulolytic enzymes. Trichoderma reesie has an efficient and well-characterized cellulase system. The major cellulases of T. reesie are cellobiohydrolases I and II, endoglucanases I and II, and beta-glucosidase. Betaglucosidase is essential for complete hydrolysis of cellulose (Itavaara et al. 1999). Artificial mixtures of cellulase systems may differ in composition or proportion from soil or compost microorganisms in nature. A cotton sample was not easily hydrolyzed using an enzyme system, but was rapidly decomposed by sludge microorganisms in the Sturm test (Itavaara and Vikman 1996).

In recent work, Nazhad et al. (2006) studied the possibilities of replacing polyethylene-coated boards with boards using a biodegradable coating. It was concluded that while this replacement might be possible, a reliable solution has not yet been found. However, the authors reported that a majority of the base-board samples tested biodegraded in a few weeks time, regardless of their coating composition.

The present work is developed from the premise that an accelerated biodegradation rate for commercial barrier coated boards could be achieved if pretreatment was done prior to the biodegradation stage, or, the living conditions of microorganisms was substantially improved. This work has also explored the recycling potential of barrier-coated boards as an alternative option to disposal in a landfill.

\section{MATERIALS AND METHODS}

\section{Materials}

Barrier-coated boards were obtained from commercial sources that supply such products to various Thailand food industries. The boards were folding boxboards, which were creased and formed into the desired shapes. The materials were: 1) bleached and internally-sized uncoated paperboard (alkenyl succinic anhydride (ASA) sizing), 2) oneside polyethylene (PE) coated paperboard with a pigment coating, 3) two-side polyethylene coated board without pigment coating, and 4) commercial liquid packaging board (LPK). The coating content (mass \%) of one-side and two-side coated boards was $5 \%$ and $13 \%$, respectively. Liquid packaging board (or multilayer laminated board) was a special product having 5 different layers of lamination. It was composed of polyethylene, aluminum, and cardboard in mass contents of $23.6 \%, 6.3 \%$ and $70.1 \%$, 
respectively in the structure $P E / A l / P E /$ cardboard/PE. Inoculum was supplied by the Department of Land Development, Thailand. It was comprised of mixed microorganisms (bacteria, fungi and actinomycetes) and a dry medium for microorganisms. The soil used for this experiment was topsoil from the northern part of Bangkok, Thailand. It was an acid sulfate soil, common in South East Asia. After retrieval from the soil, samples are wet and virtually coated with soil debris. Washing the debris from the samples is a tedious job; however, this method is traditionally used for burial experimentation

\section{Methods}

The objective was to investigate the effects of: 1) freezing treatment, 2) microbial population, 3) surface area, and 4) the type of paperboard on the biodegradation of commercial coated boards. The biodegradation potential of the samples was estimated by burying the boards in soil and monitoring changes in weight and tensile strength as a function of burial time. For the freezing experiments, boards were conditioned at $-20^{\circ} \mathrm{C}$ for one month. This was done to simulate the fact that many food packaging boards are subjected to freezing temperatures during their use. The sample sizes were $45 \mathrm{~mm} \times 15$ $\mathrm{mm}$ (rectangular), $26 \mathrm{~mm} \times 26 \mathrm{~mm}$ (small square), and $150 \mathrm{~mm} \times 150 \mathrm{~mm}$ (large square). Tests were done in both the machine-direction (MD) and cross-direction (CD) of the samples. To test the influence of either sample size or shape on biodegradation, the double-side PE coated board was used. For this sample, the edges of the board were the only accessible sites to the microorganism activity. Microorganisms could not penetrate through polyethylene coating in a time frame comparable to base-board (Nazhad et al. 2006), so the coating layer remains intact during the biodegradation process.

Given typical papermachine fiber orientation effects, the MD direction suggests more access to fiber ends, while the CD direction suggests more access to fiber sides. The magnitude of this difference depends on the type of the papermachine. The sample referred as small square (SQ) has the same area of the rectangular sample, but they are of course different in shape. The specific details of the soil condition and burying process are reported elsewhere (Nazhad et al. 2006).

The ash and moisture content of paperboard were measured according to TAPPI Standard T211 om-93 and TAPPI Standard T412 om-94, respectively. Polyethylene (PE) content of the boards was measured by subjecting them to hydrolysis in sulfuric acid $\left(92 \% \mathrm{H}_{2} \mathrm{SO}_{4}\right)$ at $80^{\circ} \mathrm{C}$. The PE film is then recovered, dried, and weighed (Andrady et al. 1992). The water vapor transmission rate (WVTR) was determined at $23^{\circ} \mathrm{C}$ and $85 \%$ RH by a Water Vapor Permeability Tester (WDDG). The testing area was $78.54 \mathrm{~cm}^{2}$. Physical properties (basis weight, caliper, tensile strength, water absorption (Cobb test), opacity, and brightness) were measured according to TAPPI standards (See the reference list). After incinerating the liquid packaging boards in a muffle furnace at $575^{\circ} \mathrm{C}$, the residue consists of ash and aluminum foil, where the aluminum foil is still in its solid form and separate from the ash. The quantity of aluminum foil was calculated using the following relation:

Amount of alu- $\quad=\quad$ weight of aluminum foil after burning $\times 100$ minum foil $(\%) \quad$ dry weight of coated board 
Moisture content and $\mathrm{pH}$ of the soil were measured according to British Standards 1377:1961 (UDC 624.131) and 1377:1961 (UDC 624.131), respectively. ASTM D42263 was used for soil texture analysis (1985d). Soil microbial population (bacteria, fungi and actinomycetes) was determined by plate count technique according to cultural methods for soil microorganism (Wollum II 1982). Organic carbon present in the soil was determined according to the method suggested by Nelson and Sommers (1982). Total nitrogen in the soil was determined using the method of Bremner and Mulvaney (1982).

The boards were recycled to study the role of a coating layer in recycling. The samples were torn into pieces with typical size of $25 \mathrm{~mm} \times 25 \mathrm{~mm}$. Repulping was performed in $25^{\circ} \mathrm{C}$ soft-water at $1.5 \%$ consistency using a British laboratory disintegrator. The samples were soaked in 2 liters of water overnight before repulping for 30,000 revolutions in a British laboratory disintegrator using $25^{\circ} \mathrm{C}$ soft-water. Pulped samples were then diluted to a consistency of approximately $0.7 \%$ (OD basis) and the debris from the coating layer was separated using a flat screen with a slot size of $0.2 \mathrm{~mm}$. Flotation was done at $0.9 \%$ consistency with the addition of $0.25 \%(\mathrm{~g} / \mathrm{g}$ od pulp) nonionic surfactant (Polyoxyethylene, Bando chemical, south Korea) using a VoithSulzer flotation cell to separate the residual stickies and other contaminants from the pulp fiber.

Table 1. Soil characteristics

\begin{tabular}{lcc}
\hline & Units & Laboratory soil \\
Parameters & & \\
\hline Moisture & $\%$ & 40 \\
pH & & 7.49 \\
Organic matter & $\%$ & 5.5 \\
Total nitrogen & $\%$ & 0.53 \\
Humidity & $\%$ & $62-91$ \\
Temperature* & $\mathrm{C}$ & $25-33.5$ \\
${ }^{*}$ The ambient temperature was variable \\
\hline
\end{tabular}

\section{RESULTS}

Table 2.

Physical characteristics of various samples (before degradation) are listed in

\section{Biodegradation of Paperboards}

The influences of paperboard texture, sample size or shape, paper directionality, freezing pretreatment, and microbial population on biodegradation were all investigated. The changes in both weight and tensile strength were used to estimate the extent of the biodegradation progress. Figure 2 shows the residual weight of large sample sizes vs. burial time, where it can be seen that the weight of the samples decreased with burial time. The weight loss for uncoated and one-side coated boards was approximately equal, and occurred at a much faster rate than the other two samples. 
Table 2. Sample Physical Characteristics

\begin{tabular}{|c|c|c|c|c|c|}
\hline \multirow[t]{2}{*}{ Parameters } & \multirow[t]{2}{*}{ units } & \multicolumn{4}{|c|}{ Samples } \\
\hline & & Uncoated & 1S coating & 2S coating & LPK \\
\hline Moisture & $\%$ & $8.3 \pm 0.24$ & $7 \pm 0.10$ & $7 \pm 0.7$ & $6.5 \pm 0.7$ \\
\hline Ash & $\%$ & $7.7 \pm 0.23$ & $5.60 \pm 0.12$ & $3.32 \pm 0.3$ & $13.6 \pm 0.2$ \\
\hline PE coating wt & $\%$ & - & $5+\overline{0} .35$ & $13.2 \overline{3}+1$ & $23.6+0.4$ \\
\hline Foil content & $\%$ & - & - & -- & $6.3 \pm 0.03$ \\
\hline Grammage & $\mathrm{g} / \mathrm{m} 2$ & $313 \pm 2$ & $306 \pm 3$ & $319 \pm 0.7$ & $29 \overline{4} \pm 2$ \\
\hline Thickness & $\mu$ & $398 \pm 2$ & $414 \pm 3$ & $442 \pm 2.50$ & $360 \pm 3$ \\
\hline Fiber length & $\mathrm{mm}$ & - & $1.15 \pm 0.01$ & $1.21 \pm 0.02$ & $1.6 \pm 0.04$ \\
\hline Coarseness & $\mathrm{mg} / \mathrm{m}$ & - & $0.16 \pm 0.01$ & $0.17 \pm 0.002$ & $0.16 \pm 0.01$ \\
\hline Cobb test & & & & & \\
\hline 1st. Face & $\mathrm{g} / \mathrm{m} 2$ & $30 \pm 1$ & 0 & 0 & 0 \\
\hline 2nd. Face & $\mathrm{g} / \mathrm{m} 2$ & $31 \pm 1$ & $31 \pm 0.01$ & 0 & 0 \\
\hline S: Side, LPK: L & packa & board & & & \\
\hline
\end{tabular}

The uncoated board sample degraded fully after seven weeks, as the samples at this time could not be retrieved for further examination. The one-side coated boards were still retrievable after 7 weeks due to the polyethylene coating. The residual weight of the one-side PE coated boards after 20 weeks of burial was almost the entire weight of the coating material (5.7\%), while the residual weight of the double-side PE coated board and liquid packaging board were $26.03 \%$ and $52.05 \%$, respectively. Degradation of double-side coated and LPK boards suggest that the enzymes diffused into the boards through the edges to degrade the unprotected cellulose.

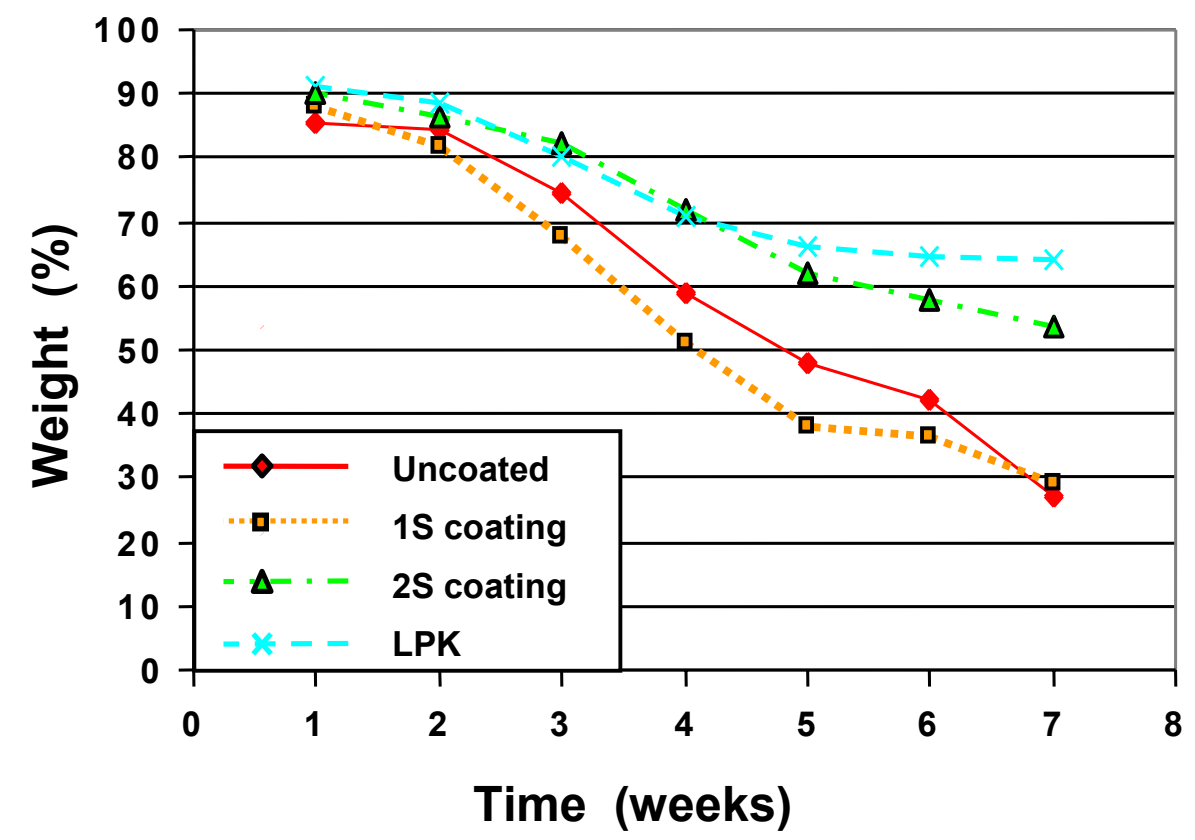

Fig. 2. Weight loss of paperboard samples 
Biodegradation was also estimated by following changes in tensile strength of the boards during burial. As Figure 3 indicates, the tensile strength of the boards deteriorated with an accelerated pace. Tensile strength of the samples (regardless of the board category) was reduced by about $90 \%$ in four weeks, while weight loss at the same $90 \%$ level needed about 12 weeks to occur. The failure of a specimen in the tensile test occurs at the weakest point. Therefore, tensile strength may potentially become severely decreased by having a very small decayed portion along the axis of the test specimen (Nazhad et al. 2006).

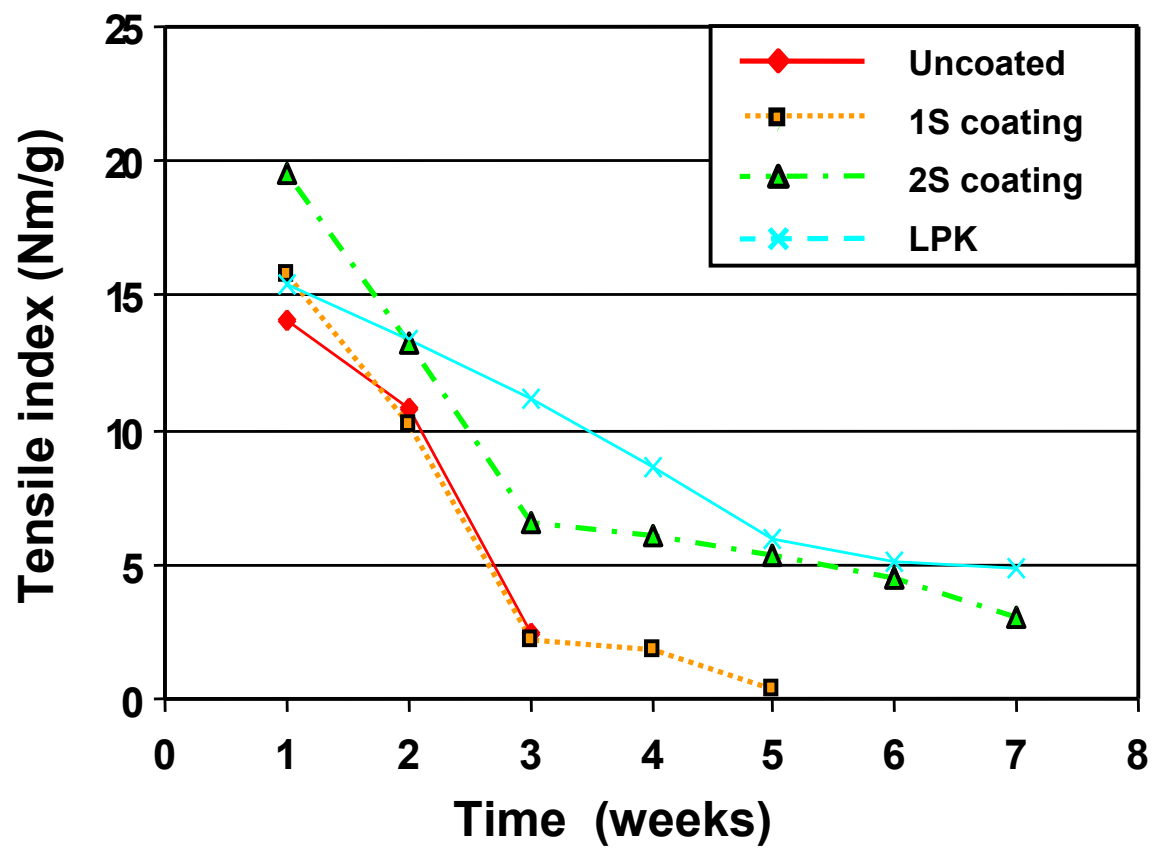

Fig. 3. Tensile strength of paperboards vs. burial time

The change in tensile strength is plotted versus weight loss for the samples in Figure 4. These data demonstrate that $50 \%$ to $80 \%$ of the tensile strength was lost during the first week of the burial process, whereby the corresponding loss in weight is about 10 $-20 \%$ for the samples. This result suggests that having a small number decayed sections along the test specimen has no real effect on weight loss.

Sample weight loss is due to migration of degraded material out of the substrate. This migration is possible of course as long as the degraded materials do not encounter any barriers along the pathway. Thus, a coating on the sample can represent a significant barrier to the migration process. This is speculated to be one of the reasons for the slow pace of weight loss of coated samples during the burial process (Nazhad, et al., 2006). 


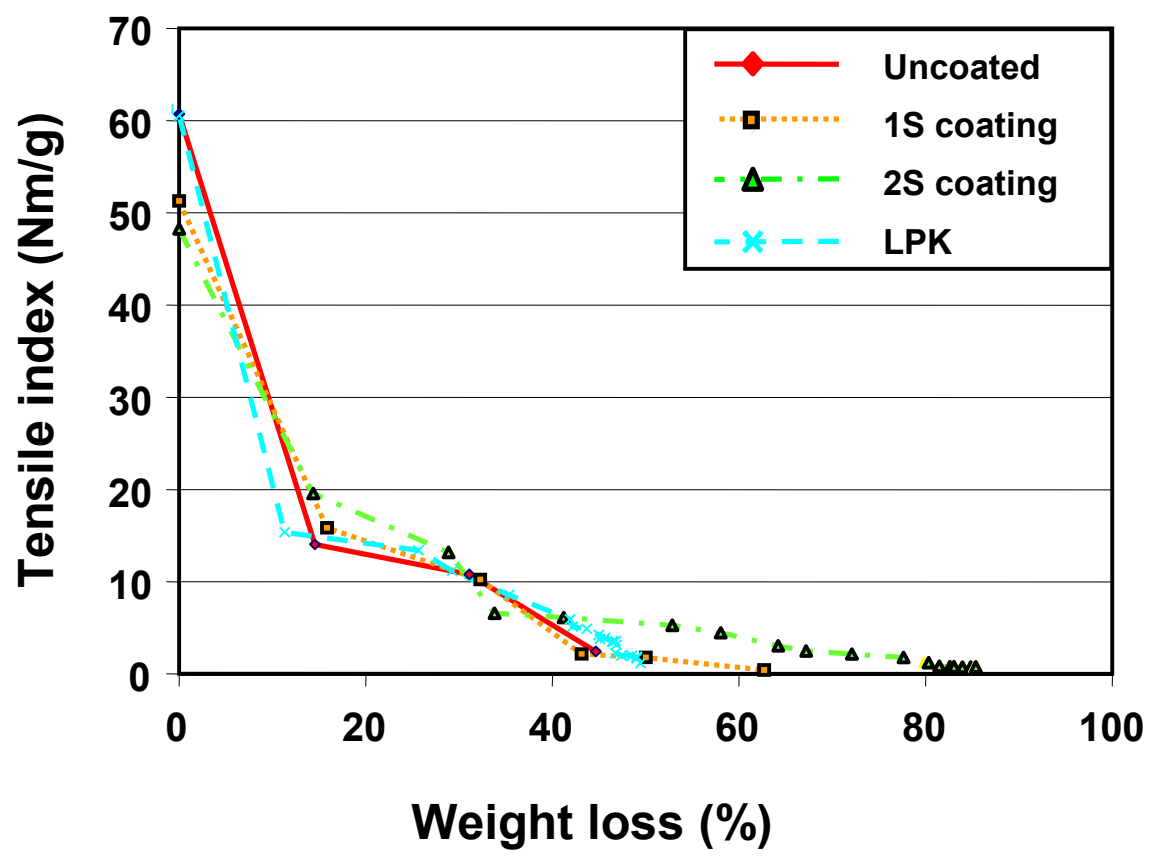

Fig. 4. Relation between tensile strength and weight loss

\section{Effect of Sample Size or Shape}

5.

The influence of the sample size or shape on biodegradation is plotted in Figure

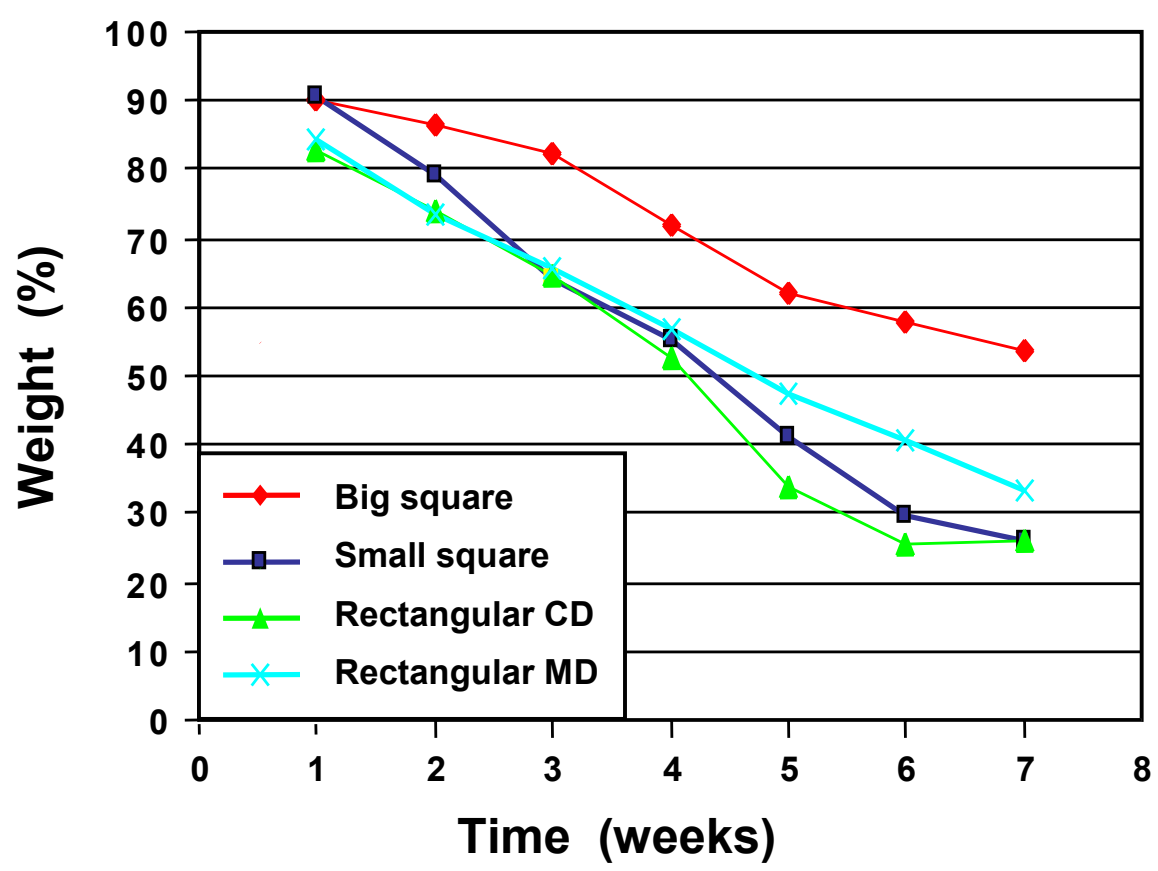

Fig. 5. Weight loss of double-side PE coated boards. 
The data in Figure 5 are for the double-side PE coated board, so only the edges were accessible sites for microorganism activity. Therefore, the smaller samples offered a greater fraction of accessible sites (based on the whole sample area) to microorganisms than the larger samples. As Figure 5 shows, the curves of the two samples that were different in shape almost coincided, while the size effect seems to be significant. This observation suggests the importance of sample size in degradation of boards. It also shows that microorganisms were not sensitive to the directionality of paper. As noted earlier, fibers in the paperboard are more oriented in the machine direction (MD) than the cross direction (CD).

\section{Effect of Freezing}

Figure 6 shows the influence of a freezing pretreatment on biodegradation, along with the effect of using inoculum. The curves of frozen and non-frozen samples are very close, indicating that prior freezing does not change the biodegradation rate. Based on this observation, it has been speculated that the freezing does not alter the structure of the boards in such a fashion that eases the base-paper decomposition. However, it does appear to make the boards brittle based on the lower elongation values seen at tensile failure.

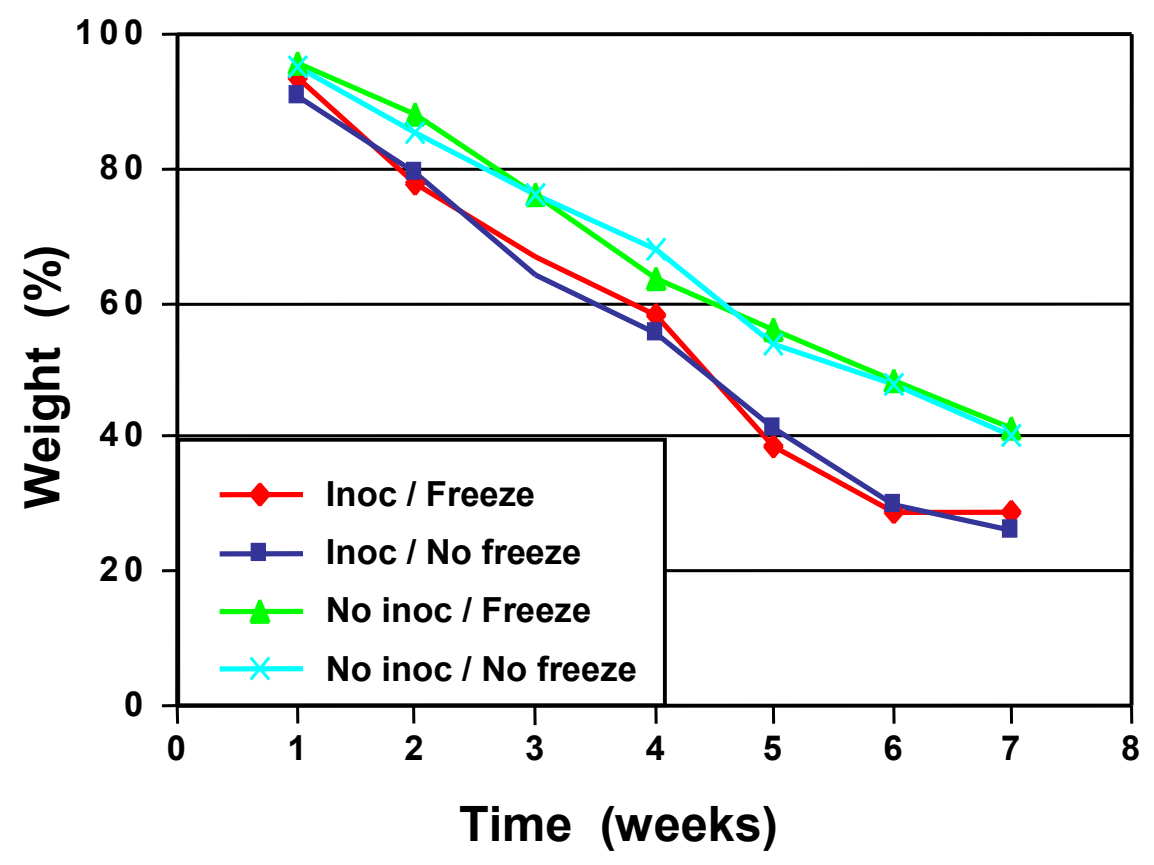

Fig. 6. Weight loss of two-side PE coated boards (frozen and non-frozen)

Freezing reduced elongation of the boards by a factor of 3 to 4 , depending on the exact structure of the boards. Addition of inoculum altered the decomposition rate somewhat. The samples which were buried in the soil mixed with inoculum exhibited more extensive weight loss, regardless of the freezing treatment (Fig. 6). 


\section{Water Vapor Transmission Rate (WVTR) and Cobb Test Values}

An attempt was made to trace biodegradation by using either the Cobb sizing test or the water vapor transmission rate (WVTR). Uncoated board could not be tested because of the development of one or more holes in the specimen during the first week. Two-side coated boards showed an increase in WVTR, but the increase was attributed to the presence of surface wrinkles, rather than changes due to mass loss by biodegradation. The data for two-side coated board only is reported in Table 3. Surface wrinkles potentially contribute in two opposing ways in determining the final outcomes. One, they reduce surface water absorption by increasing the contact angle (due to roughness effects); two, they can increase water absorption by initiating cracks in the coating layer or sized surface. One-side coated boards could only be tested for three weeks, but they also formed surface wrinkles. LPK boards did not show any change based on Cobb values.

Table 3. Cobb values of double-side coated boards at different stages of soil burial $\left(\mathrm{g} \mathrm{H}_{2} \mathrm{O} / \mathrm{m}^{2}\right)$

\begin{tabular}{|c|c|c|c|c|c|}
\hline \multirow{3}{*}{$\begin{array}{c}\text { Parameters } \\
\text { Time } \\
\text { (week) }\end{array}$} & \multirow{3}{*}{ Side } & \multicolumn{4}{|c|}{ Sample } \\
\hline & & \multicolumn{2}{|c|}{ Microbial inoculum } & \multicolumn{2}{|c|}{ No microbial inoculum } \\
\hline & & F- treatment & No treatment & F- treatment & No treatment \\
\hline \multicolumn{6}{|l|}{ 2S coating } \\
\hline 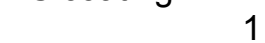 & A & 0.25 & 0.05 & 0.1 & 0 \\
\hline & B & 0.05 & 0.1 & 0 & 0 \\
\hline 2 & A & 0 & 0 & 0.5 & 0 \\
\hline & B & 0 & 0 & 0 & 0 \\
\hline 3 & A & 0.2 & 0.1 & 0 & 0.3 \\
\hline & B & 0.2 & 0.2 & 0 & 0 \\
\hline 4 & A & 0.1 & 0.4 & 0.3 & 0.4 \\
\hline & B & 0 & 0.1 & 0.3 & 0.3 \\
\hline 5 & A & 0.3 & 0.6 & 0.6 & 0.8 \\
\hline & B & 0.4 & 0.6 & 0.3 & 0.5 \\
\hline
\end{tabular}

A: Top side; B: Bottom side; F: Freezing

Soil mixed with microorganisms for frozen and non-frozen samples may exhibit an increasing trend in the WVTR values with progress of biodegradation (Fig. 7). However, the data could also be interpreted as inconclusive, and therefore should be used with caution as a potential indicator of biodegradation. 


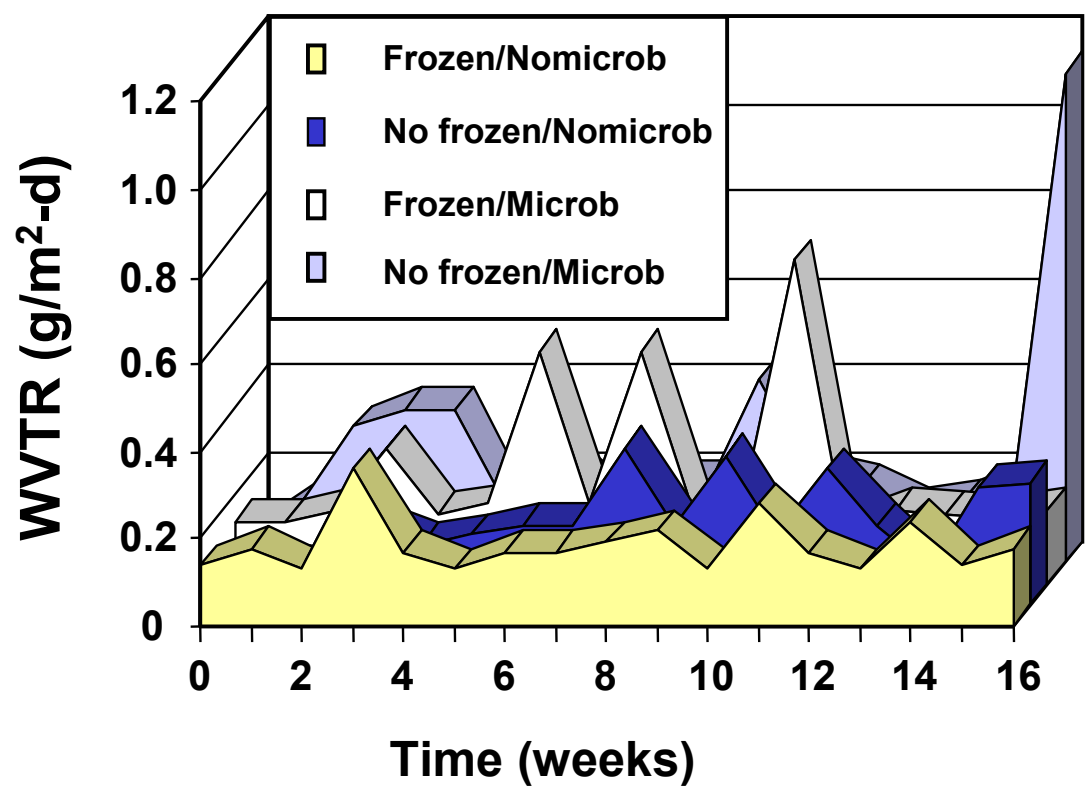

Fig. 7. WVTR for double-side coated board

\section{Recycling}

Table 4 shows the fiber yield and fiber properties after pulping and screening. As can be seen, it appears that the rejects from the board samples are correlated with the coating weight. Coating mass percentages of one-side coated, two-side coated, and liquid packaging board were $5 \%, 13 \%$, and $30 \%$, respectively. This observation suggests that the fibrous materials of the boards could be essentially fully recovered by screening. Flotation rejects were mostly fibers, fines or fillers, rather than pieces of polyethylene coating. Therefore, flotation is not recommended if the polyethylene particle size in the process of repulping is kept at macroscopic scale. As has been reported earlier, samples were collected from commercial sites, and thus specific information on the characteristics of the each baseboard was not available. However, the papermaking properties we found of the pulps are in the expected range of typical carton boards.

Table 4. Recycling of the coated boards

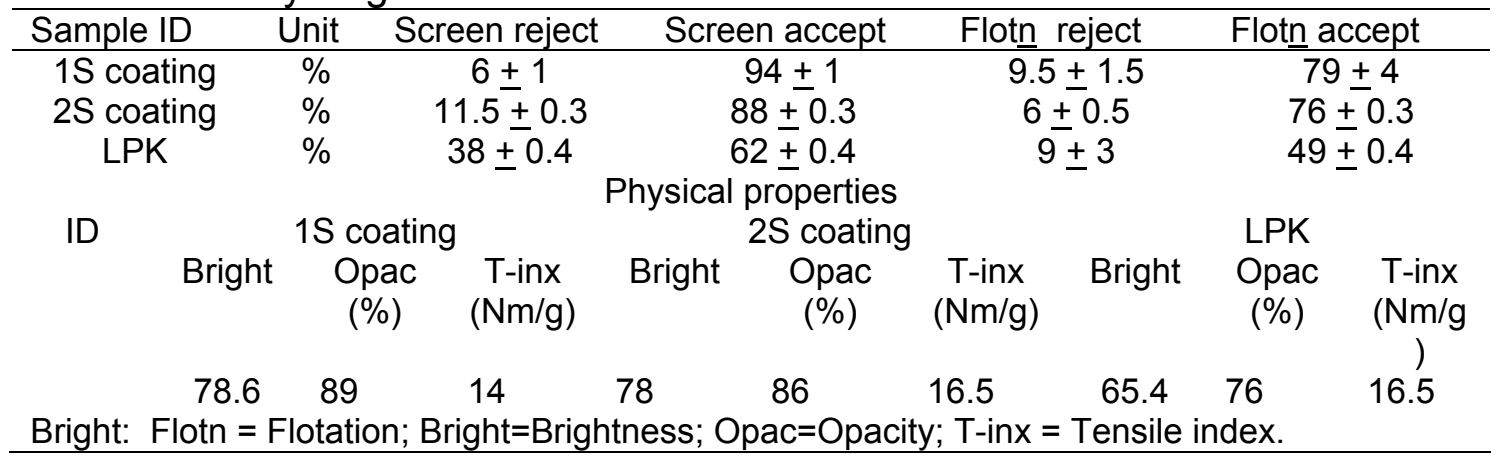




\section{DISCUSSION}

This work shows that the cellulosic substrates of barrier-coated boards are biodegradable in a time frame of weeks or months, but not their coating layers. For example, biodegradation of polyethylene by microorganisms is a very slow process. It has been reported that polyethylene remained intact after 12 years of soil burial (Potts 1978). This has been attributed to its three dimensional structure, its high molecular weight, and its hydrophobic nature. It is assumed that to increase the rate of PE biodegradation, the structure should be altered, or perhaps the molecular weight should be reduced.

The present observations highlight the importance of sample size with respect to the rate of the degradation process. It was noted earlier that the sites accessible to microorganisms were the sample edges, due to the fact that the double-side polyethylene coated samples were used for this experiment. Therefore, edge-wise penetration was the only available route to the microorganisms. In contrast to the sample size, the sample shape did not have any significant effect. The directionality of paper also did not contribute in changing the degradation process. Therefore, it is inferred that one way to accelerate the biodegradation process might be to crumple the boards prior to their exposure in order to reduce the effective size.

The observations made here also suggest that microorganisms are not sensitive to fiber orientation. If microorganisms were attracted to fiber-ends more than the fibersides, as has been previously reported (Ramose et al.1993; Nazhad et al. 1995), then degradation in MD direction should be more extensive. The present experiments could not support this type of behavior in microorganisms, at least those used in this work.

This work also suggests that the barrier-coated boards are recyclable. The baseboard could be easily separated from the coating layer by screening, and the fibers then recycled to produce a board comparable to the original product. The coating layer could be incinerated to produce energy. It has been reported that the heat value of polyethylene is higher than some of polyester-coated materials (Sridach et al. 2006).

\section{CONCLUSIONS}

1. The base-board of four different barrier-coated paperboards was found to be biodegradable in a soil environment, but the coating layer remained intact during the course of biodegradation.

2. Sample size and microbial population affected the rate of the biodegradation process, but the directionality of the samples or freezing treatment did not.

3. There was no preferential affinity of the microorganisms used to fiber-ends as compared to fiber-sides.

4. The coating layer of the sample boards was easily separated by disintegration followed by screening. The pulp yield was almost equivalent to the original weight of the base-board alone. . 


\section{REFERENCES CITED}

Andrady, A. L., Parthasarathy, V. R., and Song, Y. (1992). "Biodgradation of paperboards: Loss in strength and weight of paperboard packaging materials under aerobic soil-exposure conditions," Tappi J. 75(4), 203-215.

Itavaara, M., Siika-aho, M. and Viikari, L. (1999). "Enzymatic degradation of cellulosebased materials," J. Environ. Polym. Degrad., 7(2), 67-73.

Itavaara, M., and Vikman, M. (1999). "An overview of methods for biodegradability testing of biopolymers and packaging materials," J. Environ. Polym. Degrad., 4(1), 29-36.

Nazhad, M. M., Ramos, L. P., Paszner, L., and Saddler, J. N. (1995). “Structural constraints affecting the initial enzymatic hydrolysis of recycled paper," Enzyme Microb. Tech. 17(1), 63-72.

Nazhad, M. M., Sridach, W., Retulainen, E., Kuusipalo, J. and Parpian, P. (2006). "Biodegradation of some barrier coated boards at different soil environment," J. Appl. Poly. Sc. 3193-3202.

Potts, J. E. (1978), "Aspects of degradation and stabilization of polymers," Jelinek, H. H. G. (eds.), Elsevier: New York.

Sridach, W., Retulainen, E., Nazhad, M.M., Kuusipalo J., and Parkpian, P. (2006), "Biodegradable barrier coating on paperboard; Effects on biodegradation, recycling and incineration,' Paperi Ja Puu-Paper and Timber 88(1), 1-12.

Tuomela, M., Vikman, M., Hatakka, A., and Itavaara, M. (2000). "Biodegradation of lignin in a compost environment: a review," Bioresource Technology 72, 169-183.

Tuomela, M., Hatakka, A., Vikman, M., Raiskila, S., and Itavaara, M. (2001).

"Biodegradation of radiolabelled synthetic lignin (14C-DHP) and mechanical pulp in a compost environment," Appl Microbiol Biotechnol 55, 492-499.

World Resources (Revised 2001), "No end to paperwork," Vendy Vanasselt (ed.), Staff of world resources program, http://earthtrends.wri.org/pdf_library/features/ene fea paper.pdf

\section{STANDARDS CITED}

Tappi Methods: Basis weight (T410 om-98); Caliper (T411 om-97); Tensile strength (T494 om-96); Cobb test (T441 om-90); Opacity (T425 om-91); Brightness (T452 om-92)

American Society for Testing Materials (1985d). "Standard Test Method for Particle-Size Analysis of Soil", Vol. 04.08, Philadelphia. ASTM D422-63.

American Society of Agronomy (1982), Wollum II, A.G, "Cultural Methods for Soil Microorganism," in Methods of Soil Analysis, Part II, Chemical and Microbiological Properties, Second Ed., Wisconsin: pp. 781-801.

American Society of Agronomy (1982), Nelson, D.W. and Sommers, L. E., "Total Carbon, Organic Carbon and Organic Matter," in, Methods of Soil Analysis, Part II, Chemical and Microbiological Properties, Second Ed., Wisconsin. pp. 539-577. 
American Society of Agronomy (1982), Bremner, J. M. and Mulvaney, C. S., "NitrogenTotal', in Methods of Soil Analysis, Part II, Chemical and Microbiological Properties, Second Ed., Wisconsin, pp. 595-622.

Article submitted: Jan. 2, 2007; Article resubmitted after formatting changes: Jan. 12, 2007; First round of reviewing completed: Feb. 5, 2007; Revised article received: April 12, 2007; Article accepted: April 13, 2007; Published April 15, 2007. 